\title{
On showing and being shown plants - a guide to methods for more than human geography
}

\author{
Hannah Pitt hannah.pitt@,uwe.ac.uk University of the West of England, Bristol UK
}

\section{Introduction}

Plants are increasingly present in human geography as they gain attention commensurate with their significance to life. Human-plant geographies lag behind their animal relations (Head and Atchison 2009) as is reflected in the relatively limited elaboration of their methodologies. Approaches such as multi-species ethnography (Kirksey and Helmreich 2010) tend to focus on fauna not flora, perhaps because it is more difficult to imagine the latter as independent agents (Head and Atchison 2009). This paper progresses more-than-human methodologies by proposing how researchers might pay closer attention to what plants do; guided by Ingold's notion of showing I attempt research with plants as more prominent agents.

To explore research as showing I describe work in community gardens with a more-than-human perspective (Whatmore 2006). I endeavoured to treat humans and nonhumans with parity, exploring not just what plants mean to people but how they contribute to gardens. Previous geographic studies of gardens suggested how to understand human-plant relations, but said less about researching plants as active agents. I looked to Ingold's work on the nature of learning $(2000,2011,2013)$ to guide research which sought to enable gardeners and plants to share their knowledge.

This approach reflects the well-established view that human life can only be understood as closely entangled with that of nonhumans (Whatmore 2006). Plants are hugely significant to human survival, not least as food, hence the significance of better understanding them (Brice 2014; Head et al 2012). Beyond this practical imperative lie ontological, epistemological and ethical reasons for involving nonhumans more directly in research (Rose 2005). Vitalist ontologies demonstrate the inaccuracy of regarding humans as the only source of agency (Bennett 2010), and attention to plants demonstrates their capacity to affect others through distinct modes of intervention (Head and Atchison 2009; Jones and Cloke 2002). What plants do is a form of livingness, and so integral to the pursuit of new geographic knowledge (Whatmore 2006). The ethical imperative pushing more-than-human geography towards plants' agency is the need to counter a habit of regarding flora as passive and insentient which has allowed humans to dominate and neglect it, with serious 
ecological repercussions (Hall 2011). As Hall argues, correcting this view by appreciating plants' intelligence and recognising their similarity to humans is a step towards treating all species more respectfully. By researching plants as agents geographers challenge human exceptionalism and might help to promote ethical responsibility for plants (Hitchings and Jones 2004; Jones and Cloke 2002).

In the next section I consider methods previously used for human-plant geography, highlighting the need for sensitivity to plant agency. I then present 'knowing through showing' and how I experimented with techniques to draw attention to plants. The final sections consider the successes and limits of these, and implications for how geographers approach research.

\section{Planty methods and how to research plantiness}

Head and Atchison characterised human-plant geographies as treating plants as individuals rather than background components of human-centred landscapes (2009, see also Hitchings and Jones 2004; Jones and Cloke 2002). This shift requires a move from methods centred on talk (e.g. Head and Muir 2006), to get closer to engagements with specific plants (Head and Atchison 2009, 237). Geographers researching gardens have been quite successful in mixing ethnographic methods to explore "every day embodied interactions with plants" (Head and Atchison 2009, 240). Hitchings and Jones used visual and walking methods together with participant observation to understand people-plant encounters in various garden situations (2004, see also Hitchings 2007b). Power followed a similar approach sensitive to nonhumans to allow plants to emerge through interactions with gardeners (2005), whilst Head et al (2004) paid attention to how organising plants in gardens interacts with different attitudes to nature. Ginn's research with experienced gardeners demonstrates that inviting them to show and talk about garden practices reveals nonhumans such as slugs (2013).

In these examples exploring gardens with gardeners allowed nonhumans to emerge as active presences, demonstrating attention to the 'livingness' central to more-than-human geography (Whatmore 2006, 606-7). One researcher applying the sensibility and attentiveness Whatmore recommends suggests it is not the methods which matter but the researcher's outlook (RichardsonNgwenya 2014). By tramping through mud, filming fields and shadowing those working there she found livingness in sugar plantations. But is it the plants we learn about or the people who work with them? Head and Atchison suggest the latter tendency: 
"We have some distance to travel in considering how we might give more voice to these particular non-humans without interposing more of ourselves in the picture"(2009, 241).

Researching gardens often reveals nonhuman presences as humans engage in people-plant encounters (Head and Muir 2006; Hitchings 2003; Hitchings and Jones 2004; Power 2005). This has allowed plants greater recognition as lively individuals (Hitchings and Jones 2004) but we learn less about the agency of different plants and how they act independent of humans.

To a degree this is inevitable for in gardens as elsewhere, humans and nonhumans are entangled and inseparable (Hinchcliffe 2010). Plants evolved with people and each relies on the other for continued existence (Head et al 2012), but this relational perspective should not obscure plants particular and varied ways of doing things (Brice 2014; Head et al 2012; Jones and Cloke 2002). Capacities including the ability to photosynthesise and to store energy as starch distinguish them from other beings (Head et al 2012, 27), but their ability to sense and respond to the environment is analogous to that of animals and works through similar chemical processes (Hall 2011). Head et al coin the term 'plantiness' to denote what it is to be a plant and encourage greater geographic attention to floral agency in its own right to correct past neglect (2012).

So how should plantiness be researched? This pursuit has looked to ethnography, following human engagements with plants to understand their affects on others (Atchison and Head 2013; Brice 2014; Head et al 2012). Head and colleagues immersed themselves in networks with wheat and paid attention to its material qualities to give the plant "a certain sort of voice" (2012, 34). Shadowing vineyard staff Brice similarly sought to become sensitive to plant agency, following workers' attention to vines and how they produce a good crop (2014). He attended to plantiness by observing workers' skills in attuning to plants as they perceived how the environment changed through tasting grape sweetness and probing soil moisture.

In these examples human-plant geographers seek to recognise what plants do and are, but research methods specifically targeted at appreciating plantiness are under-examined. Relying on ethnography which is typically a human-centric method risks "trying to speak for" the plant instead of allowing its own voice (Head et al 2012, 34). The intention of attending to all kinds of beings is a good start, but might be enhanced by methods tailored to plants, hence I explored some possible strategies informed by Ingold's work on knowing and learning. Ingold inspires more-than-human geographers because his ecological outlook sees humans and nonhumans as comparable (2000, 2011 , 2013). He argues, for example, that making a basket is akin to plant growth as human-maker and growing-plant are skilled beings working with life's flows $(2011,2013)$. He suggests the 
researcher's task is to follow these flows, an ambition which resonates with more-than-human geography's pursuit of livingness. Ingold does not provide explicit methodological guidance but his writing on learning and knowledge contains valuable insights for researchers, and offers examples of how people discover nonhumans. Following his lead I experimented with ways to learn from and about plants, and came to appreciate what was from preventing me from fully apprehending plantiness. I shall discuss these attempts after elaborating Ingold's understanding of showing.

\section{Knowing by showing}

To show something to somebody is to cause it to be seen or otherwise experienced - whether by touch, taste, smell or hearing - by that other person. It is, as it were, to lift a veil off some aspect or component of the environment so that it can be apprehended directly (Ingold 2000, 21-2).

According to Ingold, novices are inducted into the world by experts who guide them through the landscape, bringing things to attention:

Placed in specific situations, novices are instructed to feel this, taste that, or watch out for the other thing. Through this fine-tuning of perceptual skills, meanings immanent in the environment - that is the relational contexts of the perceiver's involvement in the world - are not so much constructed as discovered (2000, 22).

Expert acts as guide, encouraging experimentation so the guided might notice aspects of the environment then engage with them. By moving through places inductees develop knowledge, not by receiving information but through "direct perceptual engagement with [our] environments" which attunes their attention (Ingold 2000, 21). An expert has "a greater capacity to sense and respond to cues in the environment" $(2000,161)$; a novice develops this skill to become more sensitive to the environment. Once shown around the novice can experience somewhere independently by engaging directly and applying new skills in relating to others (Ingold 2000, 22). The guide tells stories which provide way-markers, the novice then explores these routes to know the world him/herself $(2011,162)$. The guided becomes more aware of the surroundings, more adept at relating to others, and in turn may tell stories showing others how to explore.

These inductions have clear parallels with doing ethnography (Pink 2009, 34), and human-plant geographers similarly seek skills in attending to the environment. Ingold hints at how to do so saying of anthropologists "our task is not to take stock of [the world's] contents but to follow what is going on, tracing the multiple trails of becoming, wherever they lead" (2011, 14). Knowledge is gathered by "going around in an environment" $(2011,160)$, attending to things with assistance 
from guides more sensitive to them. As Brice notes those who work with plants are skilled in attuning to their environment, and by attending to how they develop and apply this skill he could understand plants (2014). Showing is a useful way to conceive such human-plant methodologies, and points to the need for methods fine-tuning researchers' attention to plantiness.

Ingold's version of learning is conducive to geographic interest in nonhumans because showing can proceed through any sense so all kinds of beings - fungi, rocks, birds - guide the novice's attention. Knowledge is not confined to humans hence plants might share their expertise in being plants. Researchers need not speak for them because the aim is to tell stories which "trace a path" for others to follow $(2011,162)$. For Ingold learning does not seek to understand past experiences, it guides future ones; ethnography does not gather data but develops skills in perception and judgement so one can engage with the world (2013). Therefore the goal of human-plant ethnography is not to represent nonhumans by speaking for them, but to tell stories of them to enable others to discover plantiness directly.

Showing as the education of attention (Ingold 2013, 2) suits human-plant geographers' task of attuning to nonhumans. By following experts' signals a researcher becomes more sensitive to nonhumans in the environment and gains skills for engaging with them in future. In previous research people expert in plants have directed geographers' attention to them as active agents (Brice 2014; Head et al 2012; Hitchings and Jones 2004). Gardeners, botanists, and horticulturalists become guides showing researcher-novices the worlds of plants, but the next step is to learn directly from plants by encouraging them to tune our attention towards their agency and characteristics. So I sought ways for plants to show what they know.

\section{Attending to nonhumans: 'Show me the garden'}

What follows is an exploration of knowing through showing, drawing on research in which I was guided into community gardens and experimented with techniques for appreciating plantiness. This was an ethnographic investigation into community gardens as places where all kinds of beings influence events and affect each other (Donati et al 2010, Hinchcliffe 2010). I wanted to know how the gardens are made, and whether involvement in this leads humans to care more for fellow gardeners, including nonhumans. The investigation was framed around invitations to 'show me the garden' both as explicit request and analytic perspective as I questioned 'what am I being shown, what am I not being shown?' As novice community gardener I looked to experts to guide my attention, developing skills to explore the gardens for myself. Here I focus on three sets of 
techniques which sought to appreciate plants' roles in community garden life by understanding plantiness.

\section{Learning through moving and attending to motion}

Motion is integral to life (Ingold 2011) and also stimulates perception (2000, 166) so moving around, attending to all kinds of movement reveals nonhuman lives. The technique which most directly mirrored Ingold's process of expert guiding novice, was walking whilst talking (Anderson 2004; Holton and Riley 2014; Kusenbach 2003) as gardeners led me on tours. Moving with others prompts talk rich in spatial knowledge (Evans and Jones 2011 ), which in gardens allows nonhumans to stimulate discussion (Hitchings and Jones 2004). Walking together guides encouraged me to tune into nonhumans they believed worth showing: "careful, that's hogweed", "taste the peppery nasturtium flower", "mmm smell those onions". Walking past trees with a very experienced gardener sparked descriptions of their forms as reflected in Latin names, like umbelliferous for umbrella shaped canopies she explained, describing the shape in a sweep of her arms. Walking around plant-rich environments encouraged gardeners to show what they know about plants to 'lift a veil' from their different ways, such as tree canopies which organise their branching to maximise efficient expose to sunlight (Hall 2011,143).

How and where people move also tunes attention to nonhumans as when one gardener stepped around a bed to avoid compressing the soil, drawing attention to roots needing to spread and access oxygen. Whilst the plantiness shown in such encounters started from human perspectives I could follow their guidance to explore plants themselves. The process of gas exchange between root and soil became clearer through a permaculture lesson when an expert explained plants' need for aerobic and anaerobic bacteria in their feeding cycles. This planty behaviour was brought to my attention by gardeners' movements and knowledge, I could then consider it from the plant's perspective.

Moving through gardens exposed me to plants' motion as when I brushed past Himalayan balsam and a seedpod burst apart, flinging seeds about with an audible pop. I became more attentive to the laden pods dangling over paths, and recognised this version of plants' capacity to disperse seed (Head et al 2012, 29). Such efficient reproduction has enabled this to become one of the UK's most reviled weeds (Mabey 2010, 259), a capacity I understood having encountered it in action. This demonstrates that researching plantiness requires researchers to attend closely to varied forms of motion, and to appreciate different movements as manifestations of plant agency. 
Learning through working with gardeners and plants

Central to ethnography is the endeavour to know the world by experiencing it as others do (Crang and Cook 2007, 37). For me this meant volunteering to do community gardening; participant observation as showing guided my attention towards things and practices important to gardeners. Garden life entails embodied engagements with nonhumans hence participation reveals how people engage with and understand plants (Hitchings and Jones 2004, 13). Working alongside one gardener I noted the difference between how he lightly handled a tender young plant as he eased it into a bed, and the careless disregard with which he tossed aside its plastic pot. Such contrasting treatment shows how people treat plants as deserving care (Hitchings 2007a) and directed my attention to plants as living things unlike inert objects: why was a living willow dome in a garden celebrated whilst a static sculpture of cut willow wands was shoved aside? The difference between living, respiring willow and dead twigs was highlighted in how gardeners treated and talked about the two.

Working with gardens can reveal plants' agency by encouraging gardeners to show what they know about this. Perception is guided by one's purpose so focuses on features of an environment useful for that intent and what they afford (Ingold 2000). When nonhumans are significant to one's intentions they are closely attended to, gardeners need to understand plant growth and the conditions required, so attending to their practices guides us towards plants capacities (Brice 2014; Head et al 2012). To learn from garden experts I invited them to show me a task then imitated their actions (Pink 2009, 34). Familiar practices are often awkward to speak of (Hitchings 2012) so I recorded demonstrations like instructional videos. This encouraged gardeners to talk through their actions and sensations so they described nonhumans. A gardener sowing seeds explained what texture the compost should be as she rubbed it between her fingers to show it was loose; to teach a novice she drew attention to conditions seeds favour. With her guidance I later tried for myself, feeling the difference between moist compost and damp soil which does not afford germination and growth.

Gardeners seek to understand nonhumans, so learning from them shows what plants do. Gardenerexperts guided me towards nonhuman agency through stories about tomato blight which drew attention to mottled leaves, in turn leading me to Phytophthora spores thriving in damp air, settling in water on leaves before entering leaf cells (RHS 2014). Stories then guided my explorations of plantiness: 
Doug the head gardener asked if I know how to pick tomatoes. He said to pick them "on the knuckle". He held his fists against each other to represent this knobble on the stem, and said taking them here keeps the green calyx attached. I looked for good ripe ones. Noticing a really red one I found its knuckle, gently tugged and it came off, calyx in tact. Others did not come so easily or hold their green top, plus I wasn't sure which were ripe enough. I tried using my thumbnail to cut the stems, but they were too tough.

Then a revelation! Looking at tomatoes with calyxes I noticed they had detached from the main stem not above the knuckle as I assumed but through a split in the knobble itself. I waggled one, sure enough the knuckle divided to free the fruit. With a few more attempts I realised this only happens with deep red fruit, under-ripe ones hold fast. Another realisation! Doug often said that "plants just want to reproduce", so if you can "make a plant think it has no seed" by removing its fruit, "it panics" and produces more. A tomato is a seed factory, and when it's ready to reproduce - ripe - it will want to fall off the plant. To harvest ripe tomatoes I should find those that come off the plant easily. And if the knuckle doesn't cleave that tomato isn't ripe (Fieldnotes).

Like many gardeners Doug spoke of plants in a manner which attributed them agency, encouraging me to regard them as purposed actors. Doug's expertise guided me towards the qualities of tomato plants but only by feeling them for myself did I understand them. He helped me develop skills for engaging with tomatoes, then tomatoes showed me how they reproduce, a key feature of plantiness (Head et al 2012, 27).

To interpret what tomatoes and other plants were showing I looked to gardening books, but these tend to focus on what gardeners should do. More useful for knowing what plants do are botanical texts that consider a plant's perspective (e.g. Chamowitz 2012; Mabey 2010). Botanists are attuned to plants' capacities to sense change, defend themselves and grow efficiently (Hall 2011), so offer guidance in how they act. This suggests fruitful cooperation between human-plant geographers and botanists in the pursuit of plantiness. It also highlights that plants' agency is distinct from the language and behaviour usually studied through ethnography. Communication through pheromones, for example, is part of plants' knowledge (Chamowitz 2012), but not something I have been trained to comprehend. When fine-tuning perception towards nonhumans such processes present a challenge, requiring modes of sensitivity not typical for social scientists. During my experiments, I identified one mode of ethnographic attention well-suited to apprehending plantiness.

Visual methods focused on plants 
It is difficult to notice plant activity because the changes are too gradual or minute to perceive, but visual methods help. Auto-photography and photo elicitation use the provocative power of images (Bell 2012; Harper 2002; Latham and McCormack 2009) to encourage gardeners to reflect on plants (Hitchings 2007b; Hitchings and Jones 2004, 12). I replicated this to compare their sensory impacts, for example lush, colourful, flowers perceived as beautiful versus messy, brown, decaying foliage stimulating disgust, to explore plants' diverse affects. Nonhumans can participate in imagery so might be more apparent in this than in other methods (Lorimer 2010). Audio-visual equipment provides a reminder to pay attention with all senses (Pink 2009), which can encourage researchers to attend to the appearance of nonhumans; for example, zoom lenses bring detail of a plant's materiality into focus.

Although imagery witnesses nonhumans (Brown and Dilley 2012; Lorimer 2010) it is still a human pointing the camera and selecting the subject. A more random, automated approach reduces the extent to which the researcher directs what is recorded. Experiments with timed cameras ${ }^{1}$ revealed more independent versions of plantiness, and allowed me to speed processes of growth to become observable. I set a weather-proof camera to take a picture every six hours over three months. Tampering and technical failures meant the images were incomplete, but they did show what happened in the garden over time including flowers' growth and movements. A similar result was achieved through repeat photography, a technique suited to understanding change (Webb et al 2010), including variations in vegetation (Crimmins and Crimmins 2008). I designated one view to photograph each time I visited a garden to create a series of images showing plants coming and going, growing and dying.

Time-lapse imagery makes plantiness more perceptible as with footage of seeds: A few days transformation from bare compost to tray of seedlings takes minutes. You can see the seedlings push aside the compost as they emerge. Watching the shadows I can see each day pass, and the seedlings rotating in synch with the sun's movements (Fieldnotes).

These pictures showed seedlings moving which, with guidance, I recognised as them sensing light and responding to it through processes of chemical release and reaction (Chamowitz 2012, chapter 5). Taking and comparing pictures and visual technology made change more noticeable, allowing detailed attention to what plants do. This technique adapted a standard ethnographic method to suit the particular form of plants' agency, the scale and speed of growth. But plants act in ways not

\footnotetext{
${ }^{1}$ I used a Brinno GardenWatchCam.
} 
so easily perceived by humans which means full appreciation of what they know may be impossible in research like this.

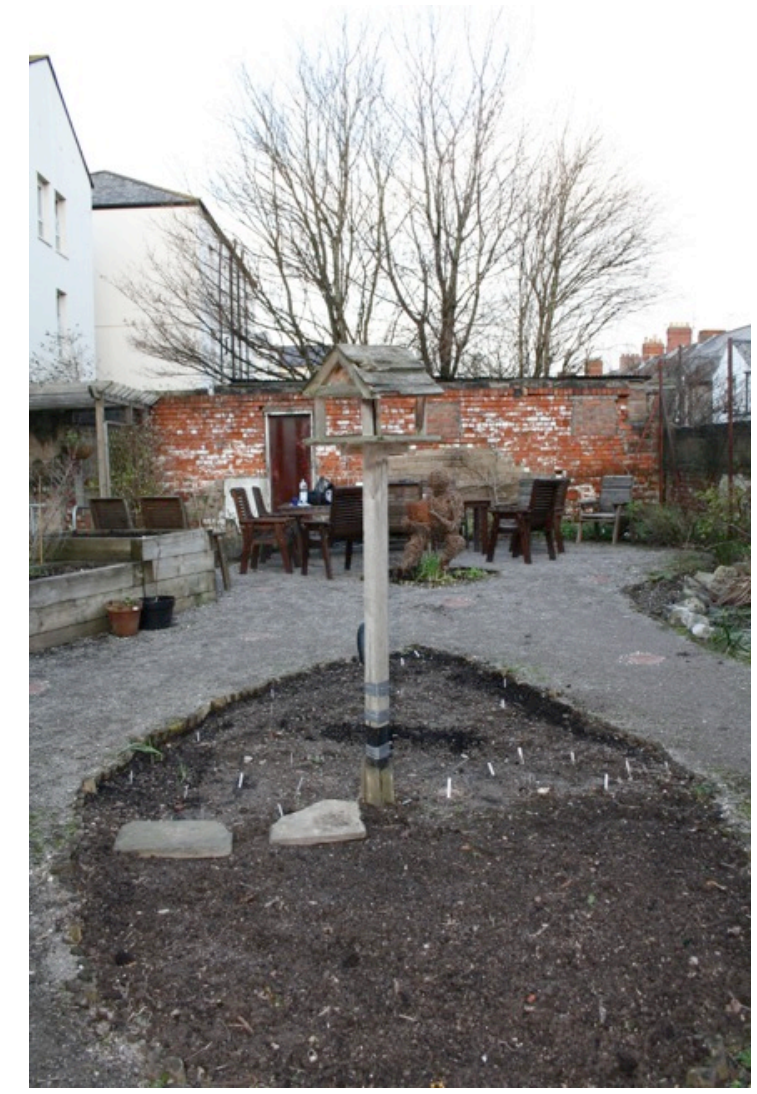

Figure 1 Winter

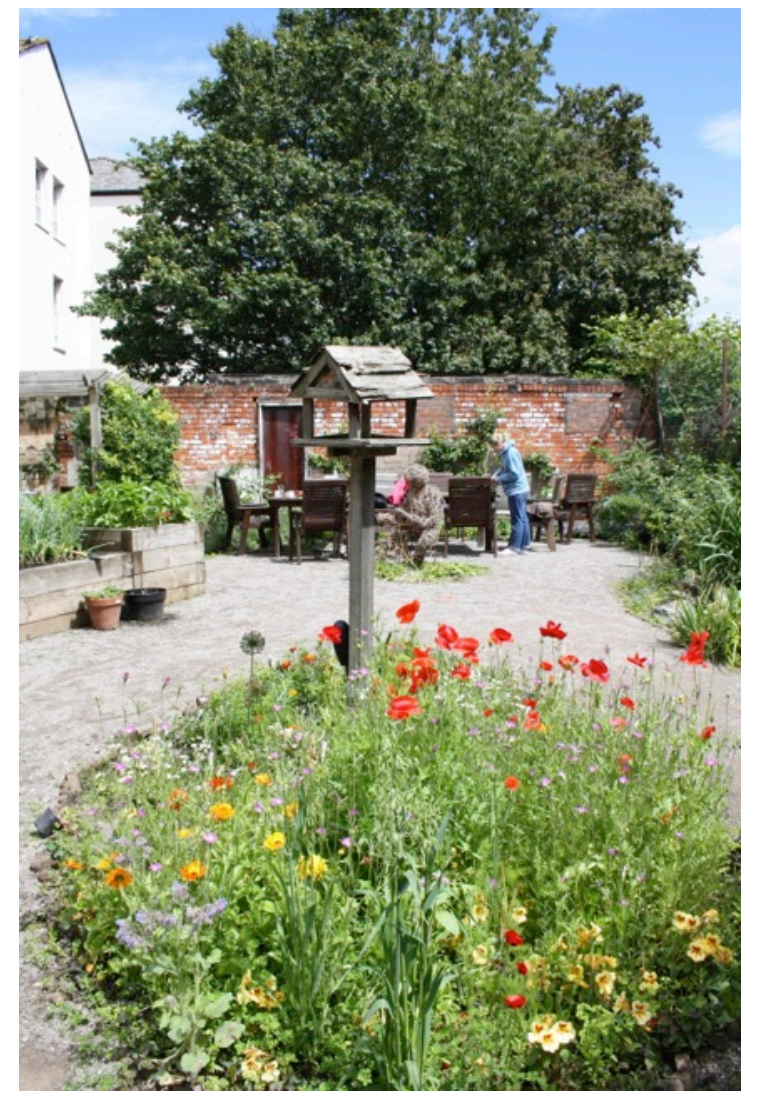

Figure 2 Summer

\section{Nonhuman guides and the limits of expertise}

The techniques described above were open to humans and nonhumans sharing what they know about community gardens, showing what it is to be plant germinating, growing, reproducing, photosynthesising. Research as showing depends on the novice-researcher encouraging knowledgeable guides to provide induction into their environment, and gardeners were often very capable guides. Allowing participants to share their stories in several ways can elicit accounts of multiple aspects of life (Hemmings 2008; Meth and McKlymont 2009). Offering several modes to show the garden also encouraged each guide to participate in a manner comfortable for them. Another benefit of this approach is regarding 'participants' as experts to disrupt conventional power dynamics of academic research (Pain 2004). But some gardeners resisted identification as experts because they had "only" taught themselves, or did not know the "proper" names of plants. These feelings might be reinforced if, as I recommend, botanists are involved in research as they may be regarded as 'more expert experts' and deter others from offering guidance. 
The techniques described demonstrate how human experts guide researchers towards nonhumans, but it is important to note limits to their expertise. Asking why a plant had died was usually answered with "I don't know". Even with my attention tuned towards spotted leaves or shrivelled fruit it was not easy to know what a plant was doing for I was not adept at understanding them, and human knowledge of plants is limited (Hall 2011, 155). Further challenges when following planty and human experts arise from ethnography's will to get close to the perspective of those being researched: what if human guides do not regard plants as active agents? Gardeners did not always bring nonhumans into focus, their attention was often directed towards people and did not necessarily recognise plants as significant actors meaning their interpretations sometimes diverged from my search for plantiness.

Attending to plants was valuable in understanding community gardens because it revealed how different plants receive different human attention, that not all are cared for and some are actively destroyed. Following their agency led me to appreciate plants as individuals which are not treated uniformly (Jones and Cloke 2002). Showing this diversity and complexity of gardeners' engagements with plants challenged a strong narrative in promotion of community gardening, the idea that it encourages people to care for nonhumans (Pitt 2014). To understand how humans treat plants and why, we need to recognise their particular agency: Himalayan balsam is very efficient at reproducing hence its status as invasive weed, whilst tomato reproduction is encouraged because it takes a tasty form. Different floral activity also offered insights into people, for example, shrivelled beans demonstrated a lack of water due to volunteers' negligence which pointed to tensions within the group which led to tasks such as watering being neglected. Through seeking to understand plantiness my research appreciated the variety of human interactions with plants, and how nonhumans affect gardens. People still loomed large and my understanding of plantiness remains limited. Additional expertise in understanding plants is required to overcome this; registering their communication for instance, would require specialist training and equipment. This implies considerable effort and resources, raising the question of how more-than-human geographers can best complement the expertise of specialists such as botanists to pursue plantiness, and to what end.

\section{Conclusion}

The methods described here suggest how human-plant geographers might understand plants as plants by following human and nonhuman guides. Research as showing encourages us to engage with guides who tune our perception towards the world's livingness to explore what it is to be plant. The techniques discussed encouraged guides to show me the garden in a manner which 
suited them, including plants able to move and reproduce, be seen and felt, or make me jump.

Diverse modes of attention were necessary to perceive beings exhibiting such different characteristics.

Doing, picturing, telling and moving with people and plants with guidance from experts reveals plantiness by fine-tuning perception to better attend to it. Attending to certain modes of plantiness is difficult for social scientists who have not been trained to understand their 'language', so we must become skilled in communicating with them or look to experts such as botanists to act as interpreters. Throughout this work we face the challenge of researching nonhumans without speaking for them (Head and Atchison 2009; Kirksey and Helmreich 2010). Ingold's vision of knowing helps by regarding the products of research as stories which guide others through their own direct engagements. The aim is not to tell about past experiences of plants but to guide future ones in which they are apprehended directly. Research as showing results in stories that prompts the reflection 'what am I being shown?' Such texts are less representations than stimulations (Crang 2005), with some onus on the viewer-reader to be active in learning from and responding to them. The advantage of this for human-plant geographers is that they are not expected to speak for plants. Any geographer negotiating the representation of those other than themselves - human or non - might seek to produce texts of this nature. In the spirit of a guide I hope my stories show some routes for such explorations.

\section{References}

Atchison J,

Eradicating invasive plant

Environment

Society and 951-968

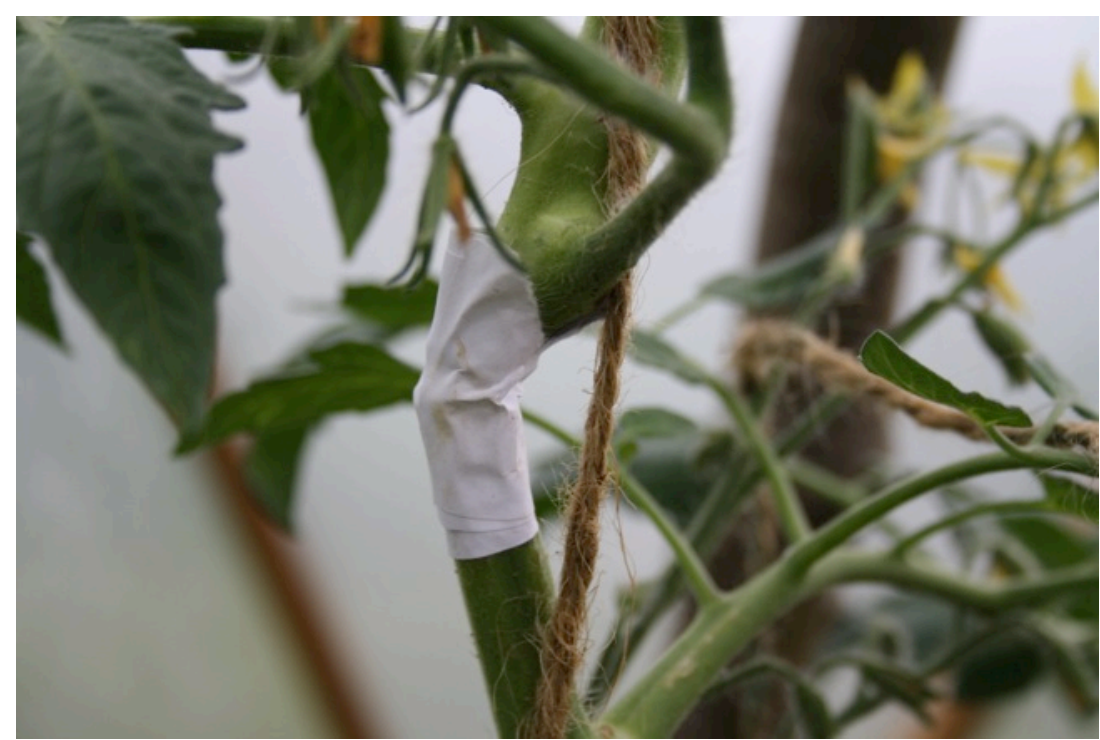

Head L, 2013, bodies in management and Planning D: Space 31(6) Figure 3 What am I being shown? Talking Anderson J 2004 whilst walking: a geographical archaeology of knowledge Area 36 254-261 
Bell V 2012 Photo-image in C Lury and N Wakeford eds Inventive Methods: The happening of the social London, Routledge 147-162

Bennett J 2010 Vibrant Matter A Political Ecology of Things. Durham, NC: Duke University Press

Brice J 2014 Attending to grape vines: perceptual practices, planty agencies and multiple temporalities in Australian viticulture Social and Cultural Geography

Brown K and Dilley R 2012 Ways of knowing for 'response-ability' in more-than-human encounters: the role of anticipatory knowledges in outdoor access with dogs Area Volume 44 37-45

Chamovitz D 2012 What a Plant Knows (Oxford Oneworld Publications)

Crang M 2005 Qualitative methods: there is nothing outside the text? Progress in Human Geography 29 225-233

Crang M and Cook I 2007 Doing Ethnographies London, Sage

Crimmins A and Crimmins T 2008 Monitoring Plant Phenology Using Digital Repeat Photography Environmental Management 41 949-958

Donati K, Cleary S and Pike L 2010 Bodies, bugs and dirt: Sustainability re-imagined in community gardens, in G. Lawrence, K. Lyons and T. Wallington (Eds.) Food Security, Nutrition and Sustainability pp207-224 (London Earthscan)

Evans J and Jones P 2011 The walking interview: methodology mobility and place Applied Geography 31 849-858

Ginn F 2013 Sticky lives: slugs, detachment and more-than-human ethics in the garden Transactions of the Institute of British Geographers

Hall M 2011 Plants as persons, a philosophical botany New York, SUNY Press

Harper D 2002 Talking about pictures: a case for photo elicitation Visual Studies 17 14-26

Head, L and Atchison, J 2009 Cultural ecology: emerging human-plant geographies Progress in Human Geography 33(2) pp236-245

Head L, Atchison J and Gates A 2012 Ingrained. A human bio-geography of wheat London, Ashgate Head L and Muir P 2006 Suburban life and the boundaries of nature: resilience and rupture in Australian backyard gardens Transactions of the Institute of British Geographers 31 505-524

Hemmings P 2008 Mixing qualitative research methods in children's geographies Area $40152-162$ Hinchcliffe S 2010 Working with multiples: a non-representational approach to environmental issues in Anderson B and Harrison P eds Taking Place London, Ashgate

Hitchings R 2003 People, plants and performance: on actor network theory and the material pleasures of the private garden Social and Cultural Geography 4 99-112

Hitchings R 2007a How awkward encounters could influence the future form of many gardens Transactions of the Institute of British Geographers 32 363-76 
Hitchings R 2007b Approaching life in the London garden centre: providing products and acquiring entities Environment and Planning A 39 242-259

Hitchings R 2012 People can talk about their practices Area 44 61-67

Hitchings R and Jones V 2004 Living with plants and the exploration of botanical encounter within human geographic research practice Ethics Policy and Environment 7 3-18

Holton M and Riley M 2014 Talking on the move: place-based interviewing with undergraduate students Area 46 59-65

Ingold T 2013 Making London, Routledge

Ingold T 2011 Being Alive London, Routledge

Ingold T 2000 The Perception of the Environment: Essays in livelihood dwelling and skill London, Routledge

Jones $\mathbf{O}$ and Cloke $\mathbf{P} 2002$ Tree Cultures: The place of trees and trees in their place Oxford, Berg Kirksey S and Helmreich S 2010 The emergence of multispecies ethnography Cultural anthropology, 25: 545-576

Kusenbach M 2003 Street Phenomenology Ethnography 4 455-485

Latham A and McCormack 2009 Thinking with images in non-representational cities: vignettes from Berlin Area 41 252-262

Lorimer J 2010 Moving image methodologies for more-than-human geographies Cultural Geographies 17 237-58

Mabey R 2010 Weeds In defence of nature's most unloved plants (London Harper Collins)

Meth P and McKlymont K 2009 Researching men: the politics and possibilities of a qualitative mixed-methods approach Social and Cultural Geography 10 909-925

Pain R 2004 Social geography: participatory research Progress in Human Geography 28: 652-663

Pink S 2009 Doing Sensory Ethnography London, Sage

Pitt H 2014. Growing Together. An ethnography of community gardening as place making, unpublished PhD thesis Cardiff University

Power E 2005 Human-nature relations in suburban gardens Australian Geographers 36 39-53

RHS 2014 Potato and Tomato Blight (http://rhs.org.uk/advice/profile?pid=217) Accessed 10 July 2014

Richardson-Ngwenya P 2014 Performing a more-than-human material imagination during fieldwork: muddy boots diarizing and putting vitalism on video Cultural Geographies 21 293-299

Rose, P 2005 Living as Part of the Whole: The Implications of Participation Journal of Curriculum and Pedagogy Volume 2, Issue 2, 2005 
Webb R, Boyer D, and Turner R eds 2010 Repeat Photography: methods and applications in the natural sciences Island Press, Washington DC

Whatmore S 2006 Materialist returns: practicing cultural geography in and for a more-thanhuman world Cultural geographies 13 600-609

\section{Photographs}

All photographs by the author.

\section{Acknowledgements}

The research on which this paper is based was funded by Cardiff University Presidents

Scholarships. Many thanks to all participants and the article referees for sharing their expertise. 